BNL-112671-2016-JA

\title{
Kinetic Phase Evolution of Spinel Cobalt Oxide During Lithiation
}

Jing Li, Kai He, Qingping Meng, Xin Li, Yizhou Zhu, Sooyeon Hwang, Ke Sun, Hong Gan, Yimei Zhu, Yifei Mo, Eric A. Stach, and Dong Su

Submitted to the ACS Nano

September 2016

Center for Functional Nanomaterials

Brookhaven National Laboratory

\author{
U.S. Department of Energy \\ USDOE Office of Science (SC), \\ Basic Energy Sciences (BES) (SC-22)
}




\section{DISCLAIMER}

This report was prepared as an account of work sponsored by an agency of the United States Government. Neither the United States Government nor any agency thereof, nor any of their employees, nor any of their contractors, subcontractors, or their employees, makes any warranty, express or implied, or assumes any legal liability or responsibility for the accuracy, completeness, or any third party's use or the results of such use of any information, apparatus, product, or process disclosed, or represents that its use would not infringe privately owned rights. Reference herein to any specific commercial product, process, or service by trade name, trademark, manufacturer, or otherwise, does not necessarily constitute or imply its endorsement, recommendation, or favoring by the United States Government or any agency thereof or its contractors or subcontractors. The views and opinions of authors expressed herein do not necessarily state or reflect those of the United States Government or any agency thereof. 


\section{Kinetic Phase Evolution of Spinel Cobalt Oxide}

\section{During Lithiation}

Jing Li ${ }^{\dagger,{ }^{*}}$ Kai He, ${ }^{\dagger}{ }^{\dagger}$ Qingping Meng, ${ }^{\dagger}$ Xin Li,${ }^{\S}$ Yizhou Zhu,,$"$ Sooyeon Hwang, ${ }^{\dagger}$ Ke Sun, ${ }^{\dagger}$ Hong Gan,,$^{\dagger}$ Yimei Zhu, Yifei Mo," Eric A. Stach,,$^{\dagger}$ and Dong Su ${ }^{*, \dagger}$

${ }^{\dagger}$ Brookhaven National Laboratory, Upton, New York 11973, USA

*Department of Materials Science and Engineering, Stony Brook University, Stony Brook 11720, USA

${ }^{\S}$ John A. Paulson School of Engineering and Applied Sciences Harvard University Cambridge, MA 02138, USA

"Department of Materials Science and Engineering, University of Maryland, College Park, Maryland 20742, USA

Corresponding author: D. Su (dsu@bnl.gov)

KEYWORDS: $\mathrm{Co}_{3} \mathrm{O}_{4}$ nanoparticles, lithium ion battery, in situ TEM 


\section{ABSTRACT}

Spinel cobalt oxide has been proposed to undergo a multiple steps reaction during the electrochemical lithiation process. Understanding the kinetics of the lithiation process in this compound is crucial to optimize its performance and cyclability. In this work, we have utilized a low-angle annular dark-field scanning transmission electron microscopy method to visualize the dynamic reaction process in real time and study the reaction kinetics at different rates. We show that the particles undergo a two-step reaction at the single particle level, which includes an initial intercalation reaction followed by a conversion reaction. At low rates, the conversion reaction starts after the intercalation reaction has fully finished consistent with the prediction of density functional theoretical calculations. At high rates, the intercalation reaction is overwhelmed by the subsequently nucleated conversion reaction and the reaction speeds of both the intercalation and conversion reactions are increased. Phase-field simulations show the crucial role of surface diffusion rates of lithium ions in controlling this process. This work provides microscopic insights to the reaction dynamics in non-equilibrium conditions and highlights the effect of lithium diffusion rates on the overall reaction homogeneity as well as the performance. 
Rechargeable lithium-ion batteries have gained tremendous attention in applications such as portable devices because of their high energy density and high voltage when compared to other battery technologies. ${ }^{1,2}$ To assure a better user experience of potable electronics, improvement of battery performance is critical, particularly to reduce the size and increase the charging rate without scarifying energy density. These requirements are reflected from a materials perspective in the demand for the development of advanced electrode materials with higher volumetric energy density and better rate capability. Specifically, with respect to rate capability, there has been significant efforts to improve material properties through both synthetic and engineering approaches, and to uncover the mechanisms of reaction through the use of multiple characterization and calculation methods. These studies have made clear the important role of kinetics in controlling electrochemical reactions within electrode materials. ${ }^{3-6}$ Transition metal oxides have attracted extensive attention since Poizot et al., demonstrated their feasibility as conversion electrode materials for lithium-ion batteries. ${ }^{7,8}$ Recent studies have shown the correlation of rate capability with microscopic reaction pathways in nickel oxides, where only a simple conversion reaction occurs. ${ }^{9}$ But, for other complex oxides with extra interstitial openings in their crystal lattices (e.g. spinel), where both lithium insertion and conversion can happen, the competitive reaction kinetics of these two reactions may affect the rate-dependent behaviors.

Spinel cobalt oxide $\left(\mathrm{Co}_{3} \mathrm{O}_{4}\right)$ has a theoretical capacity of $890 \mathrm{mAh} / \mathrm{g}$, making it an important candidate for anodes. ${ }^{10-13}$ Its structure is in the form of $\mathrm{AB}_{2} \mathrm{O}_{4}$, where $\mathrm{A}$ and $\mathrm{B}$ sites are both cobalt, but A is at the tetrahedral $8 \mathrm{a}$ (Wyckoff) site and B is at the octahedral 16d site. Thackeray et al. have investigated the reaction mechanism of the chemical lithiation of $\mathrm{Co}_{3} \mathrm{O}_{4}{ }^{10} \mathrm{In}$ the initial stage of lithiation, Li-ions are inserted into spinel $\mathrm{Co}_{3} \mathrm{O}_{4}$, displaced and push the $\mathrm{Co}^{2+}$ at the $8 \mathrm{a}$ site into the adjacent octahedral 16c site, to form a rocksalt structure $\left(\mathrm{Li}_{\mathrm{x}}(\mathrm{Co})_{16 \mathrm{c}}\left[\mathrm{Co}_{2}\right]_{16 \mathrm{~d}} \mathrm{O}_{4}(\mathrm{x}<1)\right.$. 
This is an intercalation process and the octahedral framework of $16 \mathrm{~d}$ site is maintained with only a very small volume change. It was suggested that $\mathrm{Li}_{x} \mathrm{Co}_{3} \mathrm{O}_{4}$ is not stable and several possible reactions would happen in the presence of the electrolyte, ${ }^{10}$ and with further lithiation, incoming Li-ions will occupy the 8a site and then push Co ions at the $16 \mathrm{~d}$ site out of the framework, thereby triggering an extrusion reaction. In the final stage of lithiation, the compound will be decomposed into a nano-composite composed of of $\mathrm{Li}_{2} \mathrm{O}$ and metallic $\mathrm{Co}$ (HCP structure) which is a conversion reaction. ${ }^{10-13}$ Totally, there are up to eight Li-ions that can be stored per formula unit. The overall reaction equation is:

$$
\mathrm{Co}_{3} \mathrm{O}_{4}+8 \mathrm{Li}^{+}+8 \mathrm{e}^{-} \rightarrow 4 \mathrm{Li}_{2} \mathrm{O}+3 \mathrm{Co}
$$

This intercalation-conversion reaction pathway provides a great platform to study kinetic effects in multiple reaction conditions within a single material. Under a certain potential, the reaction kinetics can be described by the Butler-Volmer equation, where current density depends on the surface over-potential and the nature of the interface between the electrolyte and electrode. ${ }^{14}$ In addition - due to local inhomogeneity present in the electrode composites - the action of side reactions and differing diffusion pathways may also strongly affect the reaction process. ${ }^{3-9}$ Because of these complicated issues, and despite intensive efforts to improve battery performance using nano-sized $\mathrm{Co}_{3} \mathrm{O}_{4}$ with different morphologies (nanowire, mesoporous, graphene-composite, nano-cage, etc.), ${ }^{15-22}$ the dynamical process that occur during the evolution of these phases is still not fully understood since the electrochemical reactions in real batteries are highly heterogeneous and can be more complicated than the scenario described in the thermodynamic equilibrium state. ${ }^{3}$

Although many studies have been able to provide structural information about the electrochemical lithiation ${ }^{23}$ there are still challenges to overcome: For example, due to the 
relaxation of the electrochemical system after discharge/charge, ex situ characterization approaches are not capable of investigating these dynamical process. ${ }^{24}$ Commonly used in situ Xray methods can probe dynamical phenomena, but such techniques may not be able to properly characterize nano-sized electrode materials, as their dimensions reach the scale of $100 \mathrm{~nm}^{24-26}$ Critically, the most often used X-ray based approaches (X-ray powder diffraction or X-ray absorption spectroscopy) also provide only global-average characterization. Alternatively, in situ transmission electron microscopy (TEM) is a specialized technique, that is able to study structural changes down to the nano to atomic scale, and has been successfully applied to study the dynamics of lithiation processes such as alloying and conversion reactions that involve significant volume changes. ${ }^{9,} 23,27-38$ However, for intercalation reactions - where the lattice parameters only change a few percent - the dynamics of phase evolution are still difficult to probe using traditional in situ TEM methods. Here, we use a strain-sensitive, low-angle annular dark-field (LAADF)-scanning TEM (STEM) technique to directly visualize the phase evolution processes that occur, even when volume change are small. ${ }^{39} \mathrm{We}$ are able to observe the intercalation reaction process of $\mathrm{Co}_{3} \mathrm{O}_{4}$ in real time during the initial discharge and the subsequent conversion reaction, at different kinetic conditions. It is observed that the rock-salt intermediate phase is always present, independent of reaction rates. We also find that the nature of the reaction may be strongly affected by the lithium diffusion onto the particles. These in situ STEM results, which are shown to be consistent with both DFT calculations and phase-field simulations, provide valuable insight into electrochemical performance at different rates.

\section{RESULTS AND DISCUSSION}


First, we investigate the electrochemical behavior of as-prepared $\mathrm{Co}_{3} \mathrm{O}_{4}$ nanoparticles using cyclic voltammetry (CV), galvanostatic discharge-charge experiments as well as the galvanostatic intermittent titration technique (GITT). Figure 1a illustrates the first three cycles of $\mathrm{CV}$ curves of the $\mathrm{Co}_{3} \mathrm{O}_{4}$ electrode cycled between $0 \mathrm{~V}$ to $3 \mathrm{~V}$ at a rate of $\mathrm{C} / 10$ (1 lithium insertion per formula in 1.25 hour). During the first cycle, a profound reduction peak was observed at $0.66 \mathrm{~V}$ that has been proposed to be caused by the initial reduction of $\mathrm{Co}_{3} \mathrm{O}_{4}$ to metallic $\mathrm{Co}{ }^{13-16}$ Meanwhile, the peak at $2.32 \mathrm{~V}$ is observed in the oxidation process, and has be assigned as oxidation of $\mathrm{Co}$ to $\mathrm{CoO}$, with the decomposition of $\mathrm{Li}_{2} \mathrm{O}$ according to ref. 18 (also as shown in Supplementary Figure S1). In subsequent cycles, the reduction peaks shift to around $0.9 \mathrm{~V}$, corresponding to the reduction of $\mathrm{CoO}$ to metallic $\mathrm{Co} .{ }^{12,19}$ Figure $1 \mathrm{~b}$ shows the discharge and charge profiles for cycles $1-3$ at a rate of $\mathrm{C} / 10$. A plateau is observed at $1.14 \mathrm{~V}$ for the first cycle. For the second and third discharge curves, the potential of the plateau increases to $1.25 \mathrm{~V}$ due to less polarization. The results of $\mathrm{CV}$ and charge-discharge profiles are consistent with the prior reports. $^{13,15-22}$

We also measured the discharge profiles at different $\mathrm{C}$ rates as shown in figure 1c. A higher capacity can be achieved at a lower rate of $\mathrm{C} / 100$ : for example, the initial capacity at $\mathrm{C} / 100$ is $1080 \mathrm{mAh} / \mathrm{g}$ while it is $725 \mathrm{mAh} / \mathrm{g}$ at $1 \mathrm{C}$. This inverse relationship between capacity and charge rate (rate capability), is commonly observed in most battery systems. For the first discharge (lithiation) cycle at rates of $\mathrm{C} / 1$ and $\mathrm{C} / 10$, we have not observed multiple plateaus that would correspond to transitions from $\mathrm{Co}_{3} \mathrm{O}_{4}$ to $\mathrm{LiCo}_{3} \mathrm{O}_{4}$ or from $\mathrm{LiCo}_{3} \mathrm{O}_{4}$ to $\mathrm{Co}$; whereas we found these two plateaus at rates of $\mathrm{C} / 50$ and $\mathrm{C} / 100$ as enlarged at the figure inset. In the curve of $\mathrm{C} / 100$, the first plateau is at about $1.23 \mathrm{~V}$ and ends at about $100 \mathrm{mAh} / \mathrm{g}$ in discharge capacity, equal to nominal $0.9 \mathrm{Li}$ insertion; then the second plateau drops to voltage of $1.20 \mathrm{~V}$. We suspect that 
those two plateaus may correspond to intercalation and conversion reactions, respectively. However, because the potential values of the plateau are changing due to the polarization at different $\mathrm{C}$ rates, it is not reliable to directly attribute these two plateaus to certain reactions. In addition, we observed the capacity at $\mathrm{C} / 100$ is even higher than the theoretical capacity (890 $\mathrm{mAh} / \mathrm{g}$ ), which should be due to the side reactions between the active material and electrolyte. ${ }^{9}$ These side reactions consuming the extra lithium result in the formation of a surface layer and are supposed to be more severe under low rate charging due to longer reaction time. ${ }^{9}$ To evaluate the state close to the equilibrium state, we have performed a galvanostatic intermittent titration technique (GITT) analysis at C/10, where at certain states of discharge we measure the open circuit voltage after a 24 hours' relaxation. We indeed observed a $0.3 \sim 0.5 \mathrm{~V}$ gap between the relaxed curve (in red dashed line) and the plateau of $\mathrm{C} / 10$. In addition, the relaxed curve has a bump that ends at around $\mathrm{x}=1$. This is consistent with the discharge curve at $\mathrm{C} / 100$, which confirmed the appearance of the first plateau at low discharge rate.

Thereafter, we performed high-resolution phase-contrast TEM (HRTEM) imaging on the $\mathrm{Co}_{3} \mathrm{O}_{4}$ sample along $<110>$ zone axis after $25 \%$ of a full discharge. At this early stage of discharge, we observed the formation of a rocksalt phase at the surface of single nanoparticles, as shown in Figure 2a. The insets of Figure 2a show the selected area fast Fourier transform (FFT) from the bulk (green) and surface (red): these correspond to the spinel and rocksalt phases, respectively. The filtered image in Figure $2 b$ further shows the distribution of these two phases. As indicated in the models of their crystal structures shown in Figure 2d-e, the spacing of one unit cell along $<110>$ projection in the spinel phase $(5.764 \AA)$ is close to that in the rocksalt phase $(6.051 \AA)$. Therefore, the interfacial strain between these two phases is supposed to be minimized, which helps to reduce the internal strain. As shown in Figure 2c, which was obtained 
from a fully lithiated sample, a composite structure is formed which contains reduced Co nanoparticles and $\mathrm{Li}_{2} \mathrm{O}$, similar to other metal oxide conversion compounds. This is confirmed by the selected area electron diffraction (SAED) and EELS spectra in Figure S1.

To investigate the dynamics of the phase evolution, we have employed an in situ dry cell technique, as utilized in previous reports. ${ }^{9,32,33,40,41}$ Since the electrochemical environment in this approach can be different from that found conventional coin cells which use an organic electrolyte, we first performed in situ electron diffraction from the sample throughout the entire lithiation process of $\mathrm{Co}_{3} \mathrm{O}_{4}$ to confirm the reaction, as shown in Figure 3 and Movie No.1. The profiles of a series of SAED are plotted as a function of reaction time, shown by a false color map in Figure 3a. From this, we extracted the SAED patterns of the pristine and fully lithiated sample, respectively, in Figure $3 b$ and Figure $3 c$. These patterns confirm that the phase transforms from spinel $\mathrm{Co}_{3} \mathrm{O}_{4}$ to a composite of metallic $\mathrm{Co}$ (HCP phase) and $\mathrm{Li}_{2} \mathrm{O}$ (Cubic phase) after the lithiation process. The diffraction profiles at 0s, 200s, 760s and 2000s are plotted and indexed in Figure 3c. We note that because of the overlapping of the peaks, e.g. $\mathrm{Co}_{3} \mathrm{O}_{4}(113) \mathrm{vs}$. $\mathrm{LiCo}_{3} \mathrm{O}_{4}$ (111) and others, it is difficult to identify the evolution of the intermediate phase $\left(\mathrm{Li}_{\mathrm{x}} \mathrm{Co}_{3} \mathrm{O}_{4}\right)$ that was confirmed by HRTEM images in Figure 2. Another in situ SAED result is shown in Figure S2 and Movie No. 2. We can trace the phase change of spinel, but it is difficult to unambiguously attribute any specific peak to the $\mathrm{LixCo}_{3} \mathrm{O}_{4}$ phase. This is because selected area diffraction samples $\sim 1$ micrometer, and thus several phases can present at the same time due to the highly inhomogeneous nature of the reaction.

Thereafter, we utilized in situ LAADF-STEM imaging to investigate the lithiation process in real space, as shown in Figures 4 and 5 as well as Movies No. 3 and 4 (accelerated by 38 times and 12 times, respectively). In case of LAADF-STEM imaging, the contrast can be attributed 
from both atomic $(\mathrm{Z})$ contrast and diffraction contrast while the contrast of a bright-field (BF)STEM image is from the mixture of diffraction contrast and phase contrast. Therefore, a BFSTEM imaging technique containing diffraction contrast, can also work in this case..$^{33}$ On the other hand, Z-contrast HAADF-STEM imaging technique is proved not sensitive to observe the intercalation reaction. The key experimental point in the utilization of this imaging technique is to use a low collection angle (the inner angle $\sim 15 \mathrm{mrad}$ in our case) to detect the contraction in the lattice induced by the strain and also to avoid bending contours. Figure 4a presents a timesequence of LAADF-STEM images at a relatively low lithiation rate. Here the overall lithiation rate is controlled by the voltage applied at the tip of the Nanofactory holder. The local diffusion rate of lithium can be affected by the overall rate but we note that no direct correlation can be made between the overall rate and local lithium concentration. In these experiments we are able to observe - from differences in both their contrast and morphology - the evolution of the spinel $\mathrm{Co}_{3} \mathrm{O}_{4}$ into the intermediate phase $\mathrm{Li}_{\mathrm{x}} \mathrm{Co}_{3} \mathrm{O}_{4}$, and finally into a composite composed of $\mathrm{Li}_{2} \mathrm{O}$ and Co. These phases are false colored with yellow, blue and red, respectively, while the raw images are shown in Figure S3. The lithiation process is driven by the diffusion of lithium ions from right to left. In the initial stage, because the lattice mismatch between $\mathrm{Li}_{\mathrm{x}} \mathrm{Co}_{3} \mathrm{O}_{4}$ and $\mathrm{Co}_{3} \mathrm{O}_{4}$ phases is only $4.74 \%$, there is obvious volume change. However, a contrast change was observed, and this contrast change is attributed to the nucleation and growth of the $\mathrm{Li}_{\mathrm{x}} \mathrm{Co}_{3} \mathrm{O}_{4}$ phase. In this experiment, it takes about 334 seconds for the spinel phase to be fully converted to the rock-salt phase. Further lithiation triggered the conversion reaction and led to a large volume expansion. Up to the end of this Movie at 600s, the conversion reaction is still not finished. The projected area as a function of reaction time is plotted in Figure $4 \mathrm{~b}$. 
We also investigated the lithiation process at a higher rate, which leads to a different reaction nature than was observed in the experiment presented in Figure 4. A time-sequence of LAADFSTEM images from this experiment is present in Figure 5a, with the phases of spinel, rocksalt and composite being false-colored with yellow, blue, and red, respectively. The corresponding raw images are presented as Figure S4. The faster lithium diffusion increased the reaction kinetics: in this condition, the conversion reaction started later than the intercalation process, but propagated in parallel through "finger-like" penetration pathways. These pathways were observed to be highly affected by the local strain and acted to increase the reaction speed. ${ }^{8}$ We measured the projected area changes as a function of time, though these measurements were necessarily approximate because of the overlap of projected images in some portions (Figure $5 b$ ). From the results of Figure $4 b$ and Figure $5 b$, we can quantify and compare the rate at which the spinel phase shrinks in size, as well as the rate of growth of the composite, as shown in Figure 5c. In our experiments, we have not observed any cases where the intercalation reaction was simply bypassed, as had proposed to occur at high rates. ${ }^{13}$ Instead, the two-step reaction is maintained, with these two phases coexisting within one single particle. Assuming that the $\mathrm{Co}_{3} \mathrm{O}_{4}$ nanoparticles have an identical surface nature, the average reaction speed observed by in situ TEM is expected to be controlled primarily by the concentration of Li ions at the surface of the $\mathrm{Co}_{3} \mathrm{O}_{4}$ nanoparticles (i.e. the lithiation rate) in our experiments. For the higher reaction speed, we suspect there is a higher $\mathrm{Li}$ concentration than is present at the lower speed: we will present simulations using the phase-field theory later in the text which support these conclusions.

The reaction pathway in equilibrium can be calculated using density functional theory (DFT) ${ }^{42-45}$ Figure $6 a$ presents calculated voltage profiles for the lithiation of $\mathrm{Co}_{3} \mathrm{O}_{4}$ to form the $\mathrm{Li}_{2} \mathrm{O}+\mathrm{Co}$ composite. The calculated profile in the equilibrium state has multiple voltage plateaus 
(green dashed line) with multiple intermediate phases, such as $\mathrm{LiCoO}_{2}, \mathrm{Li}_{2} \mathrm{CoO}_{2}$ and $\mathrm{Li}_{5} \mathrm{CoO}_{4}$. Given both that $\mathrm{LiCo}_{3} \mathrm{O}_{4}$ is an intermediate phase experimentally observed from HRTEM imaging and the nature of two-step reaction, we also considered an alternative route (red solid line), which includes the intercalation plateau $\left(\mathrm{Li}+\mathrm{Co}_{3} \mathrm{O}_{4} \rightarrow \mathrm{LiCo}_{3} \mathrm{O}_{4}\right)$ and the conversion plateau $\left(\mathrm{LiCo}_{3} \mathrm{O}_{4} \rightarrow \mathrm{Li}_{2} \mathrm{O}+\mathrm{Co}\right)$. The ground state $\mathrm{LiCo}_{3} \mathrm{O}_{4}$ structure used in the DFT computation is constructed based on the structure observed in the HRTEM images in Figure 2, consistent with the proposed $\mathrm{Li}$ ions intercalation process. However, experimentally, the twoplateau profile (red) is only observed at very low discharge rate, as shown in Figure 1c. As shown by the in situ results in Figure 4, high current/lithium supply may kinetically modify the reaction pathways. Here, we simulated the process by which $\mathrm{Li}$ ions insert into the structure using a non-equilibrium phase-field simulation, developed by Bazant and his collaborators. ${ }^{46,47}$ To describe the diffusion behavior of Li ions and the phase evolution (Figure 6b), we have combined the Butler-Volmer equation (Eq. (3) ) for the surface of electrolyte and particles,

$$
\frac{\partial c}{\partial t}=I_{0}\left[\exp \left(-\frac{\alpha n e \eta}{k_{B} T}\right)-\exp \left(\frac{(1-\alpha) n e \eta}{k_{B} T}\right)\right]
$$

and the Cahn-Hilliard model (Eq. (4) for the interior of particles: ${ }^{46}$

$$
\frac{\partial c}{\partial t}=\nabla M c \nabla(\Delta \mu)
$$

to simulate the revolution of phase. The resulting chemical potential is thus: ${ }^{48}$

$$
\Delta \mu=\frac{\partial f}{\partial c}-\kappa \nabla^{2} c
$$

This derives from the homogeneous concentration dependent free energy $(f)$ and the CahnHilliard gradient energy coefficient $(\varkappa)$. The other parameters in equation (3) and (4), as well as additional numerical details can be found in the Supporting Information. In comparison with our 
previous calculation, we have further included a contribution from strain energy due to the volume extension during the conversion reaction. Additionally, $\boldsymbol{\eta}$ is the activation overpotential; $n e$ is the net charge transferred from the solution to the electrode; $k_{B}$ is Boltzmann's constant and $T$ is temperature. In order to study how current affects the nature of the reaction, we have used two different current values of 0.001 and 0.01 in the simulations. Figures $6 \mathrm{c}-\mathrm{d}$ present time-sequenced $\mathrm{Li}$ composition profiles inside the crystal at different currents, as determined from Movies No. 5 and 6. The nature of the reaction shown in Figure 4-5 are reproduced very well by these simulations. First, the rock-salt $\mathrm{LiCo}_{3} \mathrm{O}_{4}$ phase (at $x=1$ ) forms with increasing Li-ion concentration at surface. The conversion reaction occurs subsequently, caused by the increased concentration of Li ions at the surface. At low rates, the conversion reaction nucleates when the intercalation reaction has nearly completed, while at high rate, the conversion reaction may nucleate early and can be overlapped with the intercalation reaction. Afterward, the conversion phase expands until the sample is fully lithiated. Both the in situ STEM experiments and the phase-field simulations capture the nature of two-steps reaction from $\mathrm{Co}_{3} \mathrm{O}_{4}$ to a composite of $\mathrm{Co}$ and $\mathrm{Li}_{2} \mathrm{O}$. In general, we have found that the dynamic lithiation process follows the multi-step procedure suggested by Thackeray et al. ${ }^{10}$. But after the formation of the rock-salt phase, we do not observe the extrusion of lithium or cobalt, which is supposed to be an intact particle with only the formation of metallic fine nanoparticles on the surface, whereas we observe the particle shrinking due to the conversion process. The absence of the extrusion process may be because they happen either at higher temperature $\left(50^{\circ} \mathrm{C}\right)$ or only in the presence of oxidizing agents. It was proposed that the fast discharge may trigger a direct conversion reaction of $\mathrm{Co}_{3} \mathrm{O}_{4}+\mathrm{Li}->\mathrm{Co}+\mathrm{Li}_{2} \mathrm{O},{ }^{13}$ however, in our in situ experiments, we did not 
observe this direct conversion reaction. Instead we found an accelerated conversion reaction which happened in parallel with the intercalation reaction.

\section{CONCLUSIONS}

We have investigated the lithiation of spinel $\mathrm{Co}_{3} \mathrm{O}_{4}$ using electrochemical analysis as well as in situ and ex situ TEM. Besides confirming the formation of $\mathrm{Li}_{\mathrm{x}} \mathrm{Co}_{3} \mathrm{O}_{4}$ through the use of highresolution TEM, we have directly visualized the dynamic reaction process in real time using ADF-STEM imaging. These in situ experiments showed that a two-step reaction occurs, wherein an initial intercalation reaction is followed by a conversion reaction. Furthermore, at high current rates, we found that a fast intercalation reaction is initiated, and that this fast reaction may lead to an intermediate state, wherein the intercalation reaction is subsequently overwhelmed by the faster propagating conversion reaction. The reaction speed of both intercalation and conversion are enhanced at high rates by fast diffusion rates of lithium ions at the surface of the material. In addition, we found that the reaction can proceed by a "finger-like" penetration mode when the process is driven at high rates, and that this may further increase the speed of the conversion reaction. Additionally, phase-field simulations describing the process are were found to match the experimental results very closely. The nature of the reaction at high rates represents the reaction scenario in a real battery, and explains why prior observations have not seen the intercalation reaction profile during lithiation. The work herein provides microscopic insights into reaction dynamics during non-equilibrium conditions and clarifies how the lithium diffusion rate affects the reaction nature in a real battery. 


\section{EXPERIMENTAL SECTION}

Materials. We have used commercial high purity $\mathrm{Co}_{3} \mathrm{O}_{4}(>99.5 \%)$ nanopowders purchased from US Research Nanomaterials, Inc. The average particle size is about $50 \mathrm{~nm}$. All solvents used, like ethyl alcohol, were analytically pure and purchased from Fisher Scientific without further purification.

Electrochemical Measurements. Composite electrode used for electrochemical measurements were prepared with $80 \mathrm{wt} \%$ active material, $10 \mathrm{wt} \%$ carbon black and $10 \mathrm{wt} \%$ polyvinylidene fluoride (PVDF) in N-methyl-2-pyrrolidone (NMP) and cast onto copper foil current collector. R2032 coin-type cells were assembled inside an argon-filled glove box with the as-prepared composite electrode as cathode and Li metal as anode. A Celgard 2400 monolayer polyethylene (PE) separator and $1 \mathrm{M}$ lithium hexafluorophosphate $\left(\mathrm{LiPF}_{6}\right)$ solution in ethylene carbonate (EC) : dimethyl carbonate (DMC) (1:1 in weight) electrolyte were used to make coin cells. Battery testing were performed on an Arbin BT2000 battery test station cycled between 0 and $3 \mathrm{~V} \mathrm{vs.} \mathrm{Li}^{+} / \mathrm{Li}$ at room temperature with different current rates $(1 \mathrm{C}, \mathrm{C} / 10, \mathrm{C} / 50, \mathrm{C} / 100)$. Each current pulse performed on Galvanostatic Intermittent Titration Technique (GITT) measurement was followed by a 20 -hour relaxation period to allow full relaxation of the open-circuit voltage $(\mathrm{OCV})$.

TEM Characterization. The samples for ex situ TEM were directly removed from the coin cell to a DMC solution inside an argon-filled glove box after being discharged/charged and then sonicated 2 minutes. This solution was subsequently dispersed onto a 300 mesh $\mathrm{Cu}$ grid coated with lacey carbon. The in situ electrochemical dry cell was assembled onto a Nanofactory TEM/STEM holder inside an Argon-filled glove box and transferred in TEM column with a sealed Argon-filled bag in order to avoid air exposure. Our results (EELS and electron 
diffraction) show the oxidation with air can be neglected. The in situ electrochemical dry cell consisted of a metallic $\mathrm{Li}$ coating on a piezo-driven Tungsten tip as the negative electrode, $\mathrm{Co}_{3} \mathrm{O}_{4}$ powder dispersed on half lacey carbon TEM grid as thepositive electrode and $\mathrm{Li}_{2} \mathrm{O}$ formed on the surface of Li source as solid electrolyte. During the lithiation process, a constant negative DC potential was applied between the $\mathrm{Co}_{3} \mathrm{O}_{4}$ electrode and the Li source (we used $2 \mathrm{~V}$ and $4 \mathrm{~V}$ for the low and high rates' discharging respectively), while capturing the lithiation process in real time by TEM or STEM imaging. In situ and ex situ TEM characterization were done on JEOL 2100F TEM equipped with a field-emission electron gun operated at $200 \mathrm{kV}$ and a high-resolution polepiece with a $0.19 \mathrm{~nm}$ point-to-point resolution. For in situ LAADF-STEM imaging, the convergence angle is about $12 \mathrm{mrad}$ and the inner collection angle is about $15 \mathrm{mrad}$. We note that a broad range of collection angles (practically, lower than $50 \mathrm{mrad}$ ) can be used for strain sensitive imaging. Analytical EELS and high-resolution HAADF imaging was performed on a Hitachi-2700C STEM, which equipped with cold field emission gun and probe aberration corrector. The diffraction data was processed using a script of "DiffTools" of Digital Micrograph (downloaded at http://www.dmscripting.com/difftools.html) and the intensity profiles were obtained by using a power law function to subtract the background.

DFT Calculation. The DFT calculations were performed using the Vienna Ab initio Simulation Package (VASP) within the projector augmented-wave approach with the Perdew-BurkeErnzerhof generalized-gradient approximation. The DFT parameters were consistent with the parameters used in Materials Project (MP). A Hubbard U term of $3.32 \mathrm{eV}$ is adopted for $\mathrm{Co}^{2+}$ and $\mathrm{Co}^{3+}$ in accordance with the MP and the previous testing. ${ }^{40-42}$ The ground-state crystal structures of $\mathrm{LiCo}_{3} \mathrm{O}_{4}$ were obtained by enumerating a number of ferromagnetic, anti-ferromagnetic and 
ferrimagnetic magnetic ordering. The voltage plateaus were obtained using the DFT energies of all relevant compounds in the $\mathrm{Li}-\mathrm{Co}-\mathrm{O}$ ternary space from the $\mathrm{MP}{ }^{43}$

The phase-field simulation was performed using the electrochemistry theory based on nonequilibrium thermodynamics developed by Bazant et al ${ }^{46,47}$ The details can be found at the supplemental information.

\section{ASSOCIATED CONTENT}

Supporting Information. Additional details on pristine material, S/TEM, theoretical calculation and in situ movies. This material is available free of charge via the Internet at http://pubs.acs.org.

\section{AUTHOR INFORMATION}

\section{Corresponding Author}

*Email: dsu@bnl.gov

\section{${ }^{\nabla}$ Present Address}

Department of Materials Science and Engineering and NUANCE Center, Northwestern University, Evanston, IL 60208, USA

\section{Notes}

The authors declare no competing financial interests.

\section{ACKNOWLEDGMENT}

This work is supported by the Center for Functional Nanomaterials, Brookhaven National Laboratory, which is supported by the U.S. Department Of Energy (DOE), Office of Basic 
Energy Science, under Contract No. DE- SC0012704. Q.M. and Yimei. Z. were supported by DOE/BES, Division of Materials Science and Engineering, under Contract No. DE-SC0012704. J.L. and E.A.S. had additional support as part of the Center for Mesoscale Transport Properties, an Energy Frontier Research Center supported by the U.S. Department of Energy, Office of Science, Basic Energy Sciences, under award \#DE-SC0012673. Yizhou Z. and Y.M. acknowledge the support of the Minta Martin award at University of Maryland, and the

computational resources from Extreme Science and Engineering Discovery Environment (XSEDE) supported by National Science Foundation Grant No. TG-DMR130142 and from University of Maryland supercomputing resources.

\section{REFERENCES}

1. Nitta, N.; Wu, F.; Lee, J. T.; Yushin, G. Li-Ion Battery Materials: Present and Future. Mater. Today 2015, 18, 252-264.

2. Tarascon, J. M.; Armand, M. Issues and Challenges Facing Rechargeable Lithium Batteries. Nature 2001, 414, 359-367.

3. Li, Y.; El Gabaly, F.; Ferguson, T. R.; Smith, R. B.; Bartelt, N. C.; Sugar, J. D.; Fenton, K. R.; Cogswell, D. A.; Kilcoyne, A. L.; Tyliszczak, T.; Bazzant, M. Z.; Chueh, W. C. CurrentInduced Transition from Particle-by-Particle to Concurrent Intercalation in Phase-Separating Battery Electrodes. Nat. Mater. 2014, 13, 1149-1156.

4. Kang, B.; Ceder, G. Battery Materials for Ultrafast Charging and Discharging. Nature 2009, 458, 190-193. 
5. Whittingham, M. S. Ultimate Limits to Intercalation Reactions for Lithium Batteries. Chem. Rev. 2014, 114, 11414-11443.

6. Goodenough, J. B.; Kim, Y., Challenges for Rechargeable Li Batteries. Chem. Mater. 2010, 22, 587-603.

7. Poizot, P.; Laruelle, S.; Grugeon, S.; Dupont, L.; Tarascon, J. M. Nano-sized TransitionMetal Oxides as Negative-Electrode Materials for Lithium-Ion Batteries. Nature 2000, 407, 496499.

8. Poizot, P.; Laruelle, S.; Grugeon, S.; Dupont, L.; Tarascon, J. M. From the Vanadates to 3d-Metal Oxides Negative Electrodes. Ionics 2000, 6, 321-330.

9. He, K.; Xin, H. L.; Zhao, K.; Yu, X.; Nordlund, D.; Weng, T. C.; Li, J.; Jiang, Y.; Cadigan, C. A.; Richards, R. M.; Doeff, M. M.; Yang, X. Q.; Stach, E. A.; Li, J.; Su, D. Transitions from Near-Surface to Interior Redox upon Lithiation in Conversion Electrode Materials. Nano Lett. 2015, 15, 1437-1444.

10. Thackeray, M. M.; Baker, S. D.; Adendorff, K. T.; Goodenough, J. B. Lithium Insertion into $\mathrm{Co}_{3} \mathrm{O}_{4}$ : A Preliminary Investigation. Solid Stale Ionics 1985, 17, 175-181.

11. Tao, L.; Zai, J.; Wang, K.; Zhang, H.; Xu, M.; Shen, J.; Su, Y.; Qian, X. $\mathrm{Co}_{3} \mathrm{O}_{4}$ Nanorods/Graphene Nanosheets Nanocomposites for Lithium Ion Batteries with Improved Reversible Capacity and Cycle Stability. J. Power Sources 2012, 202, 230-235.

12. Fu, Z.; Wang, Y.; Zhang, Y.; Qin, Q. Electrochemical Reaction of Nanocrystalline $\mathrm{Co}_{3} \mathrm{O}_{4}$ Thin Film with Lithium. Solid State Ionics 2004, 170, 105-109. 
13. Larcher, D.; Sudant, G.; Leriche, J. B.; Chabre, Y.; Tarascon, J. M. The Electrochemical Reduction of $\mathrm{Co}_{3} \mathrm{O}_{4}$ in a Lithium Cell. J. Electrochem. Soc. 2002, 149, A234.

14. Newman, J.; Thomas-Alyea, K. E. Electrochemical Systems. 3rd ed.; John Wiley \& Sons, Inc.: 2004.

15. Li, Y.; Tan, B.; Wu, Y. Mesoporous $\mathrm{Co}_{3} \mathrm{O}_{4}$ Nanowire Arrays for Lithium Ion Batteries with High Capacity and Rate Capability. Nano Lett. 2007, 8, 265-270.

16. Wang, L.; Liu, B.; Ran, S.; Huang, H.; Wang, X.; Liang, B.; Chen, D.; Shen, G. Nanorod-Assembled $\mathrm{Co}_{3} \mathrm{O}_{4}$ Hexapods with Enhanced Electrochemical Performance for Lithiumion Batteries. J. Mater. Chem. 2012, 22, 23541.

17. Pan, A.; Wang, Y.; Xu, W.; Nie, Z.; Liang, S.; Nie, Z.; Wang, C.; Cao, G.; Zhang, J. G. High-Performance Anode Based on Porous $\mathrm{Co}_{3} \mathrm{O}_{4}$ Nanodiscs. J. Power Sources 2014, 255, $125-$ 129.

18. Xu, M.; Wang, F.; Zhao, M.; Yang, S.; Song, X. Molten Hydroxides Synthesis of Hierarchical Cobalt Oxide Nanostructure and Its Application as Anode Material for Lithium Ion Batteries. Electrochim. Acta 2011, 56, 4876-4881.

19. Huang, G.; Xu, S.; Lu, S.; Li, L.; Sun, H. Micro-/Nanostructured $\mathrm{Co}_{3} \mathrm{O}_{4}$ Anode with Enhanced Rate Capability for Lithium-Ion Batteries. ACS Appl. Mater. Interfaces 2014, 6, 72367243.

20. Shaju, K. M.; Jiao, F.; Debart, A.; Bruce, P. G. Mesoporous and Nanowire $\mathrm{Co}_{3} \mathrm{O}_{4}$ as Negative Electrodes for Rechargeable Lithium Batteries. Phys. Chem. Chem. Phys. 2007, 9, $1837-1842$. 
21. Wu, Z. S.; Ren, W.; Wen, L.; Gao, L.; Zhao, J.; Chen, Z.; Zhou, G.; Li, F.; Cheng, H. M. Graphene Anchored with $\mathrm{Co}_{3} \mathrm{O}_{4}$ Nanoparticles as Anode of Lithium Ion Batteries with Enhanced Reversible Capacity and Cyclic Performance. ACS Nano 2010, 4, 3187-3194.

22. Yan, N.; Hu, L.; Li, Y.; Wang, Y.; Zhong, H.; Hu, X.; Kong, X.; Chen, Q. $\mathrm{Co}_{3} \mathrm{O}_{4}$ Nanocages for High-Performance Anode Material in Lithium-Ion Batteries. J. Phys. Chem. C 2012, 116, 7227-7235.

23. Liu, X. H.; Huang, J. Y. In Situ TEM Electrochemistry of Anode Materials in Lithium Ion Batteries. Energ. Environ. Sci. 2011, 4, 3844-3860.

24. Liu, H.; Strobridge, F. C.; Borkiewicz, O. J.; Wiaderek, K. M.; Chapman, K. W.; Chupas, P. J.; Grey, C. P. Batteries. Capturing Metastable Structures during High-Rate Cycling of $\mathrm{LiFePO}_{4}$ Nanoparticle Electrodes. Science 2014, 344, 1252817.

25. Kao, Y. H.; Tang, M.; Meethong, N.; Bai, J.; Carter, W. C.; Chiang, Y. M. OverpotentialDependent Phase Transformation Pathways in Lithium Iron Phosphate Battery Electrodes. Chem. Mater. 2010, 22 , 5845-5855.

26. Chueh, W. C.; El Gabaly, F.; Sugar, J. D.; Bartelt, N. C.; McDaniel, A. H.; Fenton, K. R.; Zavadil, K. R.; Tyliszczak, T.; Lai, W.; McCarty, K. F. Intercalation Pathway in Many-Particle $\mathrm{LiFePO}_{4}$ Electrode Revealed by Nanoscale State-of-Charge Mapping. Nano Lett. 2013, 13, 866872.

27. Huang, J. Y.; Zhong, L.; Wang, C. M.; Sullivan, J. P.; Xu, W.; Zhang, L. Q.; Mao, S. X.; Hudak, N. S.; Liu, X. H.; Subramanian, A.; Fan, H.; Qi, L.; Kushima, A.; Li, J. In Situ 
Observation of the Electrochemical Lithiation of a Single $\mathrm{SnO}_{2}$ Nanowire Electrode. Science 2010, 330, 1515-1520.

28. Gu, M.; Li, Y.; Li, X.; Hu, S.; Zhang, X.; Xu, W.; Thevuthasan, S.; Baer, D. R.; Zhang, J.-G.; Liu, J.; Wang, C. In Situ TEM Study of Lithiation Behavior of Silicon Nanoparticles Attached to and Embedded in a Carbon Matrix. ACS Nano 2012, 6, 8439-8447.

29. Wang, C. M.; Xu, W.; Liu, J.; Zhang, J. G.; Saraf, L. V.; Arey, B. W.; Choi, D.; Yang, Z. G.; Xiao, J.; Thevuthasan, S.; Baer, D. R. In Situ Transmission Electron Microscopy Observation of Microstructure and Phase Evolution in a $\mathrm{SnO}_{2}$ Nanowire during Lithium Intercalation. Nano Lett. 2011, 11, 1874-1880.

30. McDowell, M. T.; Ryu, I.; Lee, S. W.; Wang, C.; Nix, W. D.; Cui, Y. Studying the Kinetics of Crystalline Silicon Nanoparticle Lithiation with In Situ Transmission Electron Microscopy. Adv. Mater. 2012, 24, 6034-6041.

31. McDowell, M. T.; Lu, Z.; Koski, K. J.; Yu, J. H.; Zheng, G.; Cui, Y. In Situ Observation of Divergent Phase Transformations in Individual Sulfide Nanocrystals. Nano Lett. 2015, 15, 1264-1271.

32. He, K.; Zhou, Y.; Gao, P.; Wang, L.; Pereira, N.; Amatucci, G. G.; Nam, K.-W.; Yang, X. Q.; Zhu, Y. M.; Wang, F.; Su, D. Sodiation via Heterogeneous Disproportionation in $\mathrm{FeF}_{2}$ Electrodes for Sodium-Ion Batteries. ACS Nano 2014, 8, 7251-7259.

33. He, K.; Zhang, S.; Li, J.; Yu, X.; Meng, Q. P.; Zhu, Y.; Hu, E.; Sun, K.; Yun, H.; Yang, X. Q.; Zhu, Y. M.; Gan, H.; Mo, Y. F.; Stach, E. A.; Murray. C. B.; Su, D. Visualizing Non- 
Equilibrium Lithiation of Spinel Oxide via In Situ Transmission Electron Microscopy. Nat. Commun. 2016, 7, 11441.

34. Nie, A.; Gan, L. Y.; Cheng, Y.; Asayesh-Ardakani, H.; Li, Q. Q.; Dong, C.; Tao, R. Z.; Mashayek, F.; Wang, H. T.; Schwingenschlogl, U.; Kile, R. F.; Yassar, R. S. Atomic-Scale Observation of Lithiation Reaction Front in Nanoscale $\mathrm{SnO}_{2}$ Materials. ACS Nano 2013, 7, 62036211.

35. Liu, Y.; Hudak, N. S.; Huber, D. L.; Limmer, S. J.; Sullivan, J. P.; Huang, J. Y. In Situ Transmission Electron Microscopy Observation of Pulverization of Aluminum Nanowires and Evolution of the Thin Surface $\mathrm{Al}_{2} \mathrm{O}_{3}$ Layers during Lithiation-Delithiation Cycles. Nano Lett. 2011, $11,4188-4194$.

36. Su, Q.; Du, G.; Zhang, J.; Zhong, Y.; Xu, B.; Yang, Y.; Neupane, S.; Kadel, K.; Li, W. In Situ Transmission Electron Microscopy Investigation of the Electrochemical Lithiation Delithiation of Individual $\mathrm{Co}_{9} \mathrm{~S}_{8} /$ Co-Filled Carbon Nanotubes. ACS Nano 2013, 7, 11379-11387.

37. Luo, L.; Wu, J.; Xu, J.; Dravid, V. P. Atomic Resolution Study of Reversible Conversion Reaction in Metal Oxide Electrodes for Lithium-Ion Battery. ACS Nano 2014, 8, 11560-11566.

38. Luo, L.; Wu, J.; Li, Q.; Dravid, V. P.; Poeppelmeier, K. R.; Rao, Q.; Xu, J. Reactions of Graphene Supported $\mathrm{Co}_{3} \mathrm{O}_{4}$ Nanocubes with Lithium and Magnesium Studied by In Situ Transmission Electron Microscopy. Nanotechnology 2016, 27, 085402.

39. Muller, D. A.; Nakagawa, N.; Ohtomo, A.; Grazul, J. L.; Hwang, H. Y. Atomic-Scale Imaging of Nanoengineered Oxygen Vacancy Profiles in $\mathrm{SrTiO}_{3}$. Nature 2004, 430, 657-661. 
40. He, K.; Lin, F.; Zhu, Y.; Yu, X.; Li, J.; Lin, R.; Nordlund, D.; Weng, T. C.; Richards, R. M.; Yang, X. Q.; Doeff, M. M.; Stach, E. A.; Mo, Y. F.; Xin, H. L.; Su, D. Sodiation Kinetics of Metal Oxide Conversion Electrodes: A Comparative Study with Lithiation. Nano Lett. 2015, 15, 5755-5763.

41. Su, Q. M.; Zhang, J.; Wu, Y. S.; Du, G. H. Revealing the Electrochemical Conversion Mechanism of Porous $\mathrm{Co}_{3} \mathrm{O}_{4}$ Nanoplates in Lithium Ion Battery by In Situ Transmission Electron Microscopy. Nano Energy 2014, 9, 264-272.

42. Ong, S. P.; Richards, W. D.; Jain, A.; Hautier, G.; Kocher, M.; Cholia, S.; Gunter, D.; Chevrier, V. L.; Persson, K. A.; Ceder, G. Python Materials Genomics (Pymatgen): A Robust, Open-Source Python Library for Materials Analysis. Comp. Mater. Sci. 2013, 68, 314-319.

43. Jain, A.; Ong, S. P.; Hautier, G.; Chen, W.; Richards, W. D.; Dacek, S.; Cholia, S.; Gunter, D.; Skinner, D.; Ceder, G.; Persson, K. A. Commentary: The Materials Project: A Materials Genome Approach to Accelerating Materials Innovation. APL Mater. 2013, 1, 011002.

44. Jain, A.; Hautier, G.; Ong, S. P.; Moore, C. J.; Fischer, C. C.; Persson, K. A.; Ceder, G. Formation Enthalpies by Mixing GGA and GGA+U Calculations. Phys. Rev. B 2011, 84.

45. Wang, L.; Maxisch, T.; Ceder, G. Oxidation Energies of Transition Metal Oxides within the GGA+U Framework. Phys. Rev. B 2006, 73, 195107

46. Bazant, M. Z. Theory of Chemical Kinetics and Charge Transfer based on Nonequilibrium Thermodynamics. Acc. Chem. Res. 2013, 46, 1144-1160.

47. Bai, P.; Cogswell, D. A.; Bazant, M. Z. Suppression of Phase Separation in $\mathrm{LiFePO}_{4}$ Nanoparticles during Battery Discharge. Nano Lett. 2011, 11, 4890-4896. 
48. Cahn, J. W.; Hilliard, J. E. Free Energy of a Nonuniform System. I. Interfacial Free Energy. J. Chem. Phys. 1958, 28, 258-267.
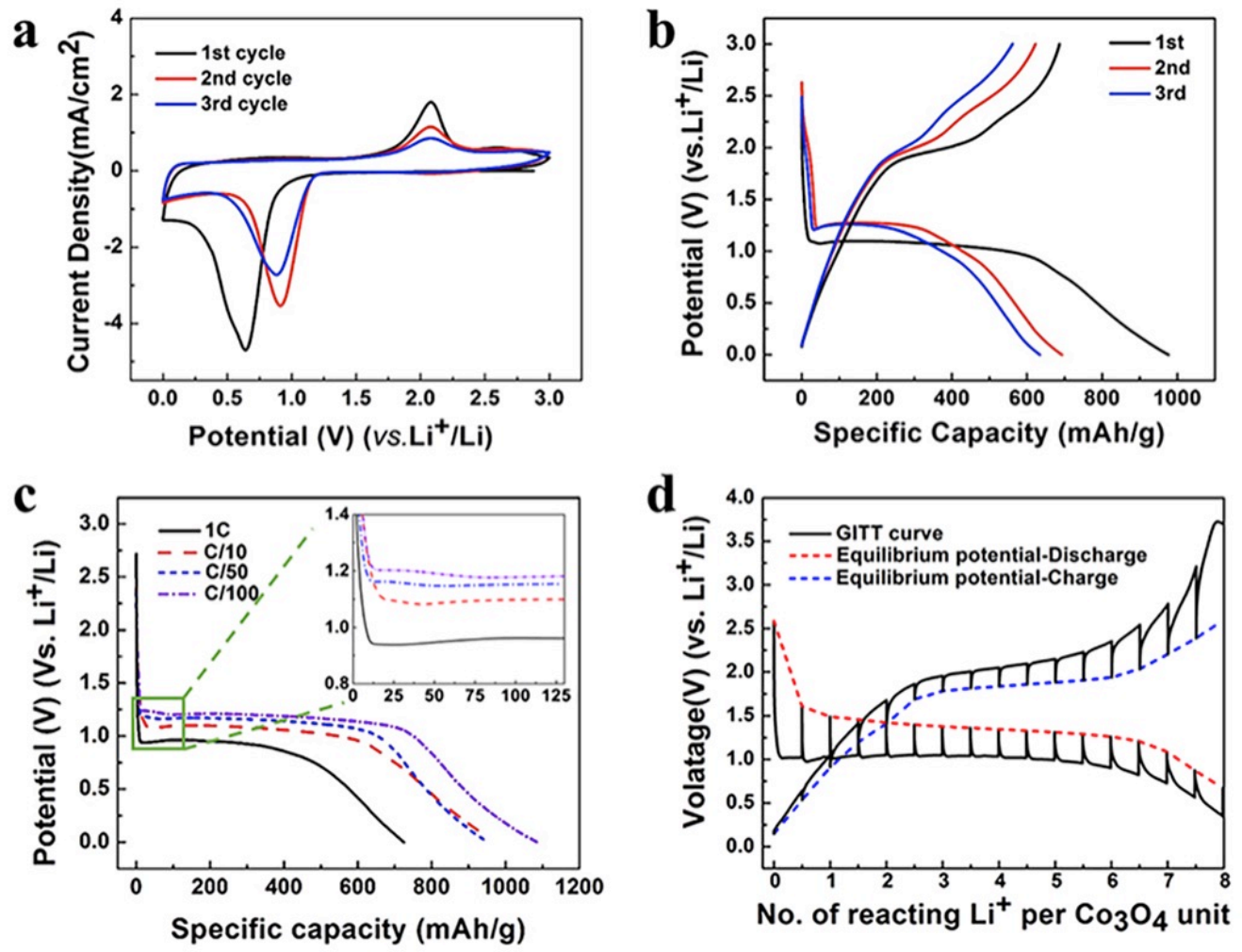

Figure 1. Electrochemical performances of $\mathrm{Co}_{3} \mathrm{O}_{4}$. (a) First three cyclic voltammogram curves of $\mathrm{Co}_{3} \mathrm{O}_{4}$ electrode in the range of $0.01-3.00 \mathrm{~V}$. (b) Discharge and charge profiles of $\mathrm{Co}_{3} \mathrm{O}_{4}$ electrode at the rate of $0.1 \mathrm{C}$ in the range of $0.01-3.00 \mathrm{~V}$. (c) Discharge profiles of $\mathrm{Co}_{3} \mathrm{O}_{4}$ electrode in the range of $0.01-3.00 \mathrm{~V}$ at rates of $1 \mathrm{C}$ (black line), $0.1 \mathrm{C}$ (red dash line), $0.02 \mathrm{C}$ (blue dash line) and $0.01 \mathrm{C}$ (violet dash line). The inset image presents magnified curves in the range of 0 to 125 $\mathrm{mAh} / \mathrm{g}$. (d) Charge and discharge galvanostatic intermittent titration technique (GITT) curves of $\mathrm{Co}_{3} \mathrm{O}_{4}$ electrode. 

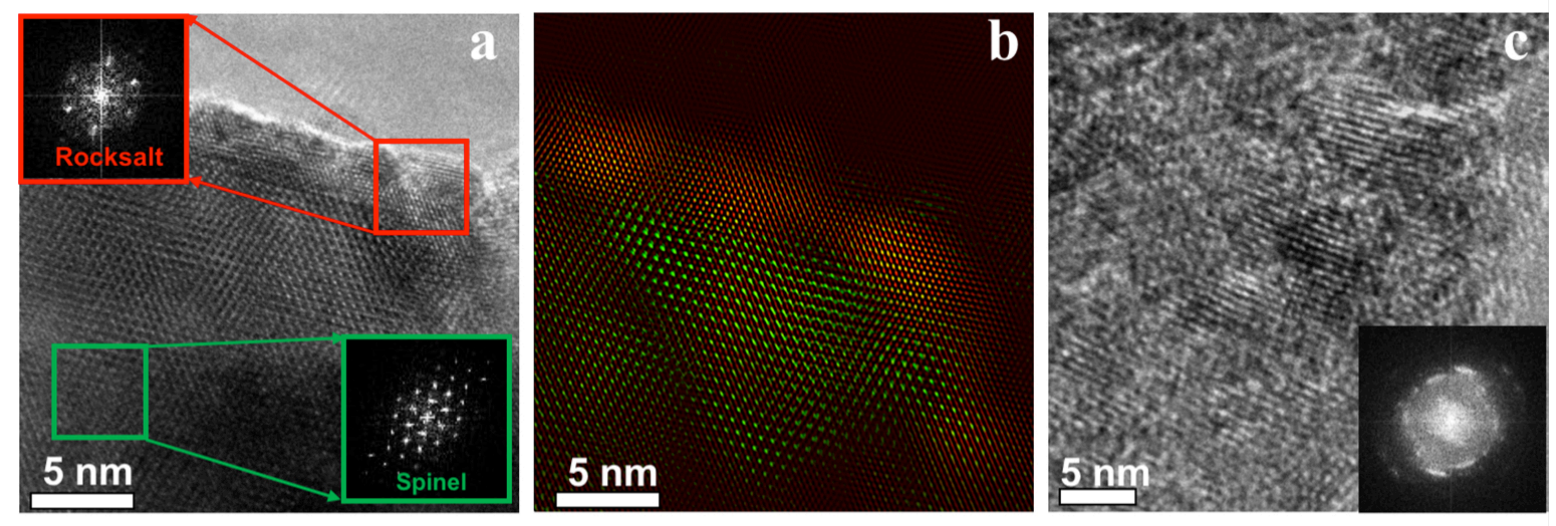

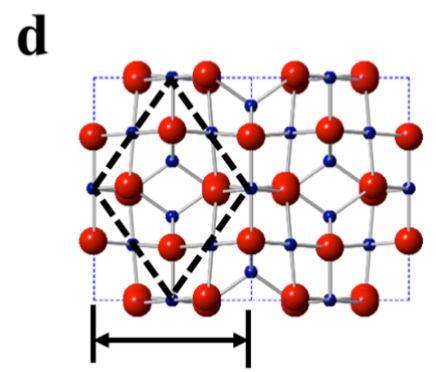

$5.764 \AA$ $\mathbf{e}$

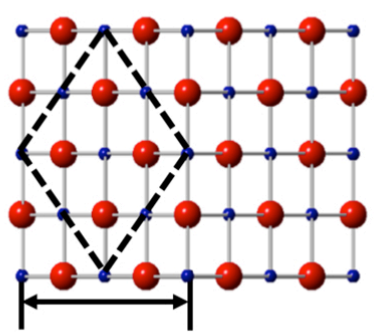

$6.051 \AA$

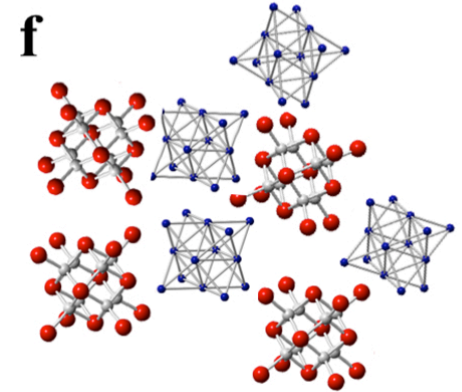

Figure 2. (a) HRTEM image of a single crystal $\mathrm{Co}_{3} \mathrm{O}_{4}$ indicating the coexistence of both spinel and rocksalt structure. Insets show the FFT of the spinel structure (orange) and rocksalt structure (blue) along the [011] zone axis. (b) Filtered images of (a) show the corresponding phase distribution by using two sets of spinel and rocksalt FFTs. (c) HRTEM images of the composite electrode after the conversion reaction. (d-f) The atomic structure of pristine $\mathrm{Co}_{3} \mathrm{O}_{4}$ with spinel structure, rocksalt $\left(\mathrm{Li}_{\mathrm{x}} \mathrm{Co}_{3} \mathrm{O}_{4}\right)$ and schematic of $\mathrm{Li}_{2} \mathrm{O}$ plus metallic $\mathrm{Co}$, respectively. 


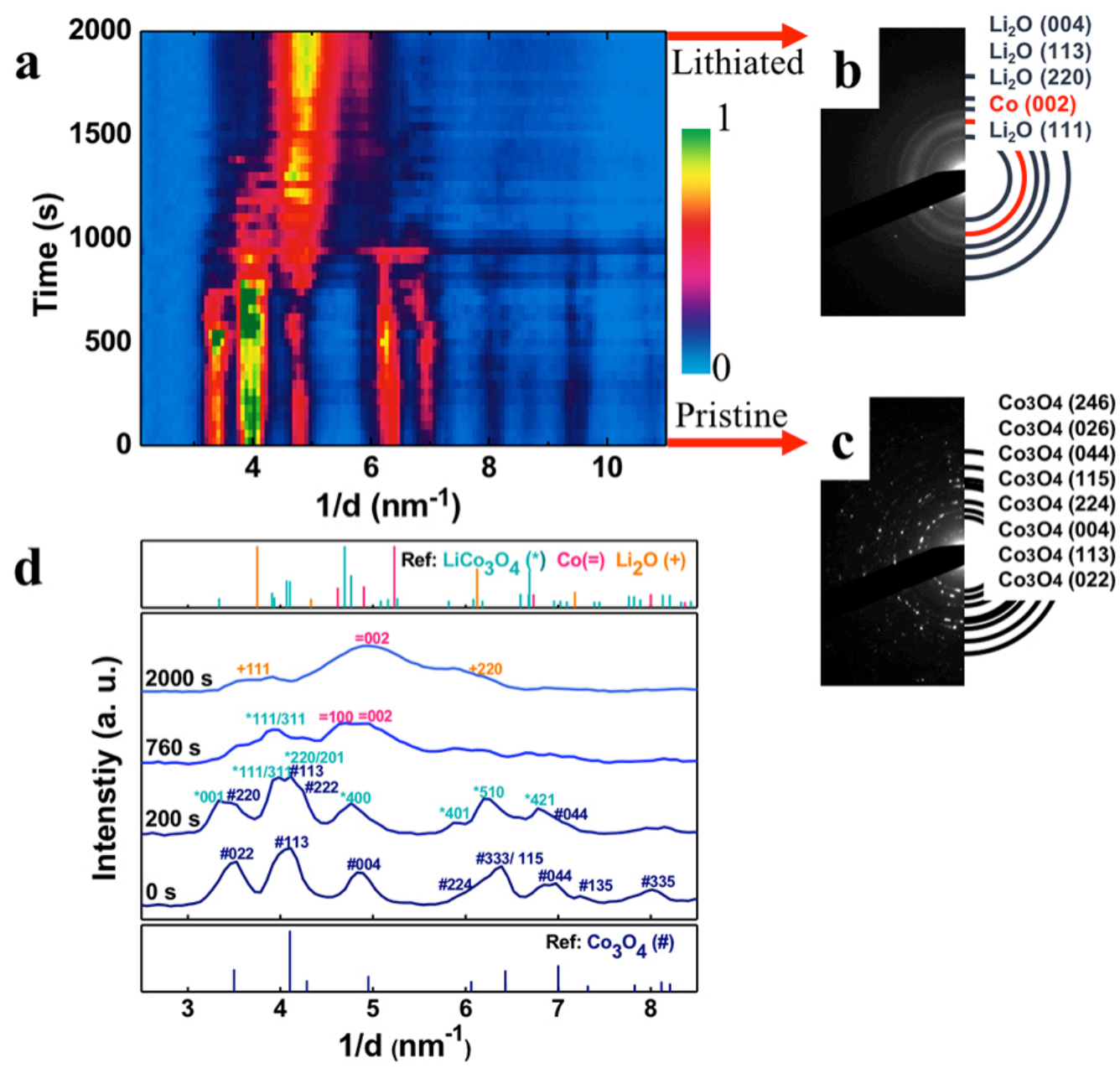

Figure 3. In situ selected area electron diffraction results, showing the phase evolution during lithiation. (a) Electron diffraction intensity profile as function of reaction time during in situ lithiation of $\mathrm{Co}_{3} \mathrm{O}_{4}$ nanoparticles. (b) and (c) shows SAED patterns corresponded with the intensity profile obtained at the lithiated (2000s) and pristine (0s) state. (d) Integrated intensity profiles at $0 \mathrm{~s}, 200 \mathrm{~s}, 760 \mathrm{~s}$ and $2000 \mathrm{~s}$ are indexed with respect to reference data of $\mathrm{Co}_{3} \mathrm{O}_{4}$, $\mathrm{LiCo}_{3} \mathrm{O}_{4}, \mathrm{Co}$ and $\mathrm{Li}_{2} \mathrm{O}$ phases. 

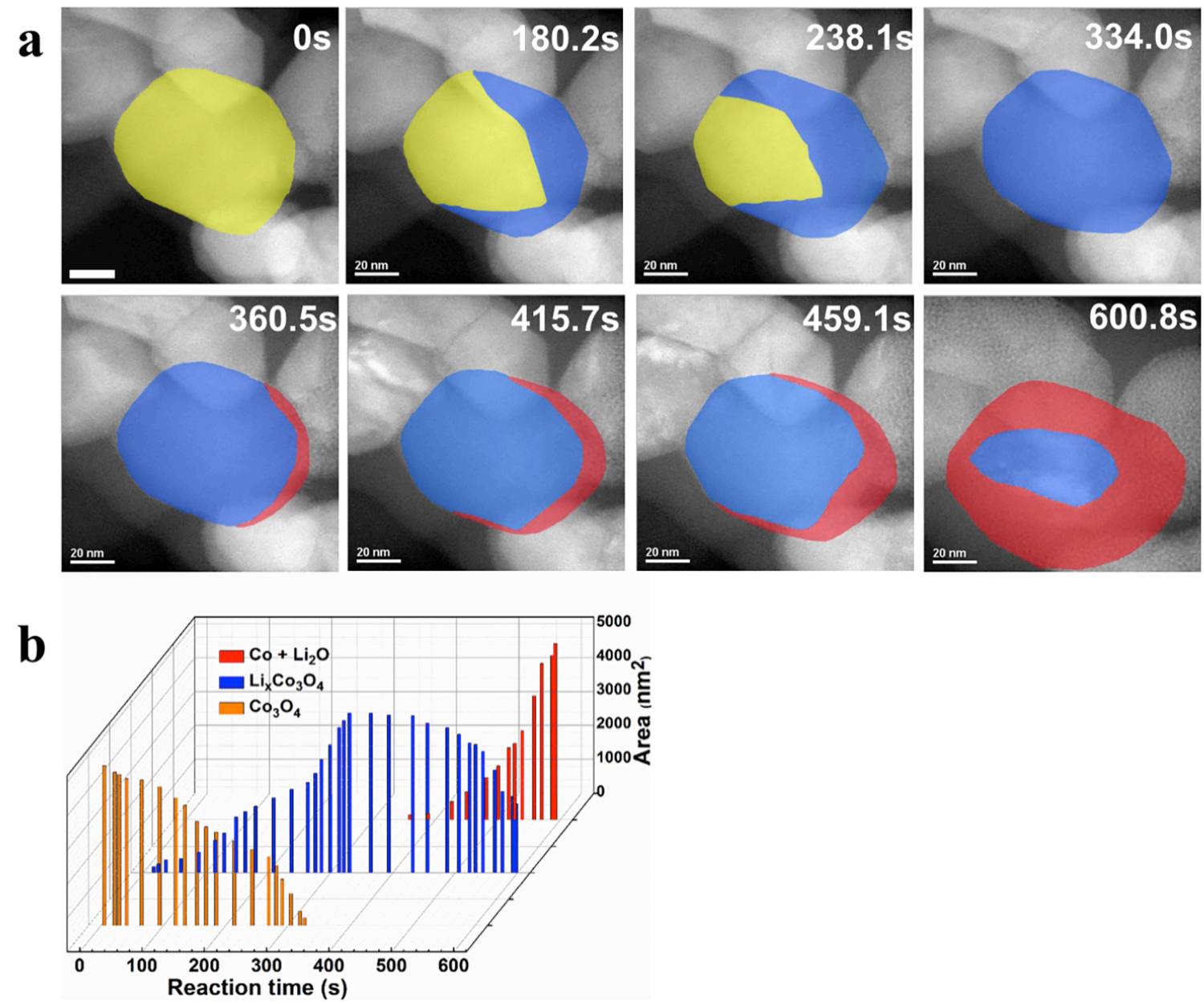

Figure 4. In situ Morphological evolution of $\mathrm{Co}_{3} \mathrm{O}_{4}$ during lithiation at a low rate. (a) LAADFSTEM image series shows phase evolution during lithiation in real time. To clarify the distribution and route of different phases, three overlaid false colors are used: yellow (pristine $\mathrm{Co}_{3} \mathrm{O}_{4}$ ), blue (intermediate phase $\mathrm{Li}_{\mathrm{x}} \mathrm{Co}_{3} \mathrm{O}_{4}$ ) and red (composition of $\mathrm{Co}$ and $\mathrm{Li}_{2} \mathrm{O}$ after conversion). Scale bar is 20nm. Raw data are presented as Supplemental Figure S3 (b) Projected areas of three phases as function of reaction time (0-600.8s). 

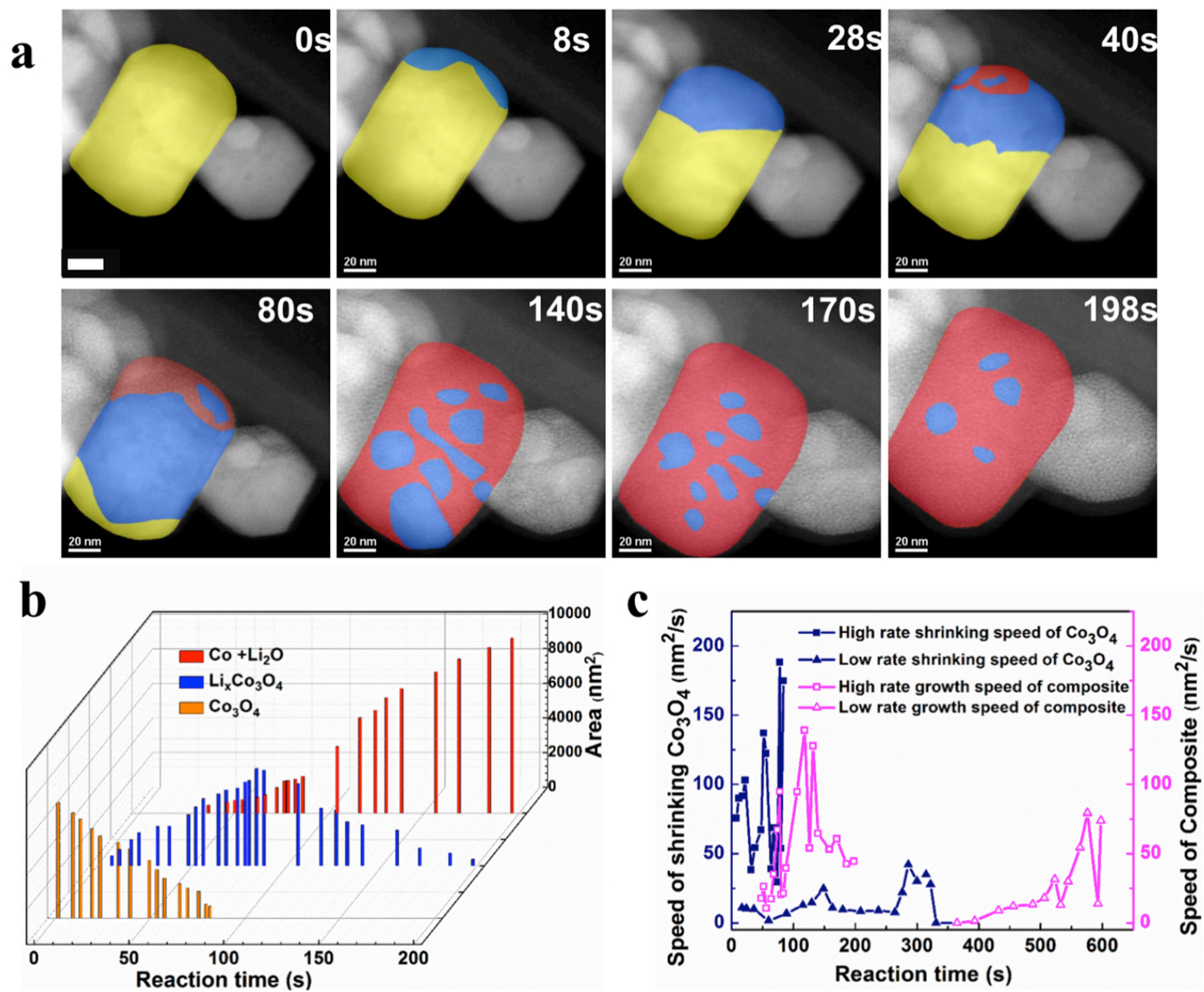

Figure 5. In situ Morphological evolution of $\mathrm{Co}_{3} \mathrm{O}_{4}$ during lithiation at a high rate. (a) The LAADF-STEM image series shows phase evolution during lithiation as function of reation time (0-244s). To clarify distribution and route of different phase, three overlaid false colors are used: yellow (pristine $\mathrm{Co}_{3} \mathrm{O}_{4}$ ), blue (intermediate phase $\mathrm{Li}_{\mathrm{x}} \mathrm{Co}_{3} \mathrm{O}_{4}$ ) and red (composition of Co and $\mathrm{Li}_{2} \mathrm{O}$ after conversion). Scale bar is $20 \mathrm{~nm}$. Raw data is presented as Supplemental Figure S4. (b) Projected area of intermediate phase $\left(\mathrm{LixCo}_{3} \mathrm{O}_{4}\right)$ as function of reaction time. (c) Comparison of shrinking/propagation speed between the results shown in Figure 4(a) and Figure 5(a). 

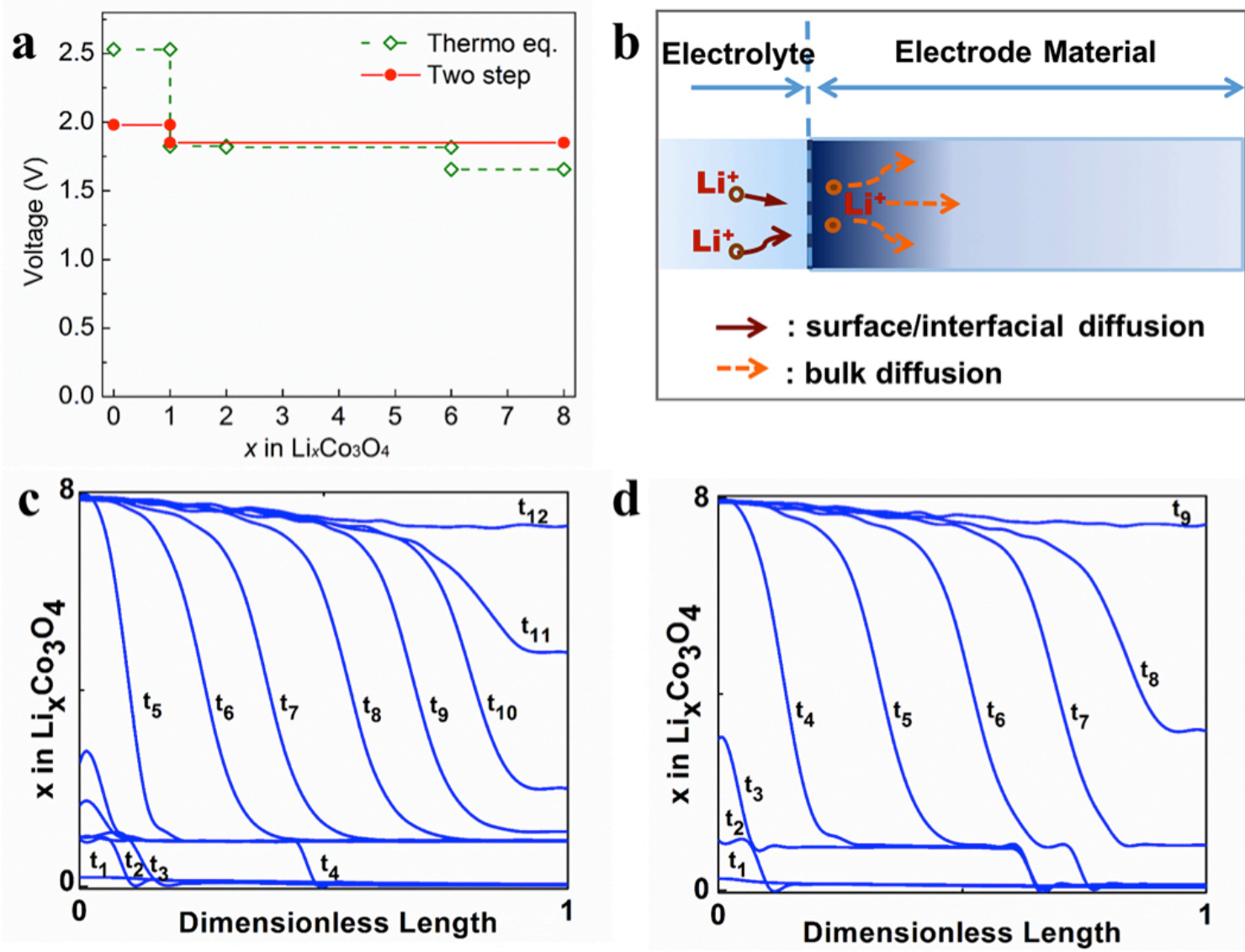

Figure 6. Theoretical calculations: (a) Discharge voltage profile as a function of Li composition in $\mathrm{Li}_{x} \mathrm{Co}_{3} \mathrm{O}_{4}(x=0-8)$ calculated from first principles calculation. The thermodynamic equilibrium reaction route is shown in green dashed lines, and the two-step reaction route is shown in red solid lines. (b) Schematic diagram illustrates the diffusion behavior of $\mathrm{Li}^{+}$ions on the surface between the electrolyte and the electrode, as well as in the interior of the electrode. (c) and (d) Li composition profiles along a one-dimensional length as a function of reaction time, as simulated by the phase-field theory (also see Movies No. 5 and No. 6). 